\title{
Zum Verhältnis von Kirche und Staat in Ungarn im Spiegel der ungarischen Diözesansynoden in der Zwischenkriegszeit.
}

\author{
TIBOR KLESTENITZ / BUDAPEST
}

Das Ungarn der Zwischenkriegszeit befand sich in einer sehr eigenartigen staatsrechtlichen Position: die Regierungsform des Landes war zwar offiziell Königtum, aber der Thron war nicht besetzt, und der Staat wurde von 1920 bis 1944 von Admiral Miklós Horthy als provisorischem Staatsoberhaupt, als Reichsverweser geführt ${ }^{1}$.

Seine Legitimation fanden aber die Royalisten nicht einwandfrei. Der letzte König, Karl IV. (als Kaiser von Österreich Karl I.) wollte nämlich seine Herrschaft nach dem Sturz der ungarischen Sowjetrepublik (1. August 1919) so bald wie möglich restaurieren, und er reiste im März 1921 in geheimer Mission nach Budapest. Der Reichsverweser aber überzeugte ihn davon, dass die Nachbarstaaten Rumänien, die Tschechoslowakei und das Königreich der Serben, Kroaten und Slowenen seine Thronbesteigung als casus belli betrachten würden. Im Oktober 1921 kehrte der König erneut zurück, dieses Mal, um den Thron mit Hilfe von royalistischen Generälen und ihren Truppen zu besteigen. Es wurde aber schnell klar, dass der Restaurationsversuch in einem Bürgerkrieg enden würde, weshalb Karl seine Pläne aufgab. Er wurde mit seiner Familie nach Madeira gebracht, und die ungarische Nationalversammlung sprach am 6. November die Entthronung der Habsburger aus ${ }^{2}$.

Das antiliberale und autoritäre Regime von Miklós Horthy betrachtete die christlichen Kirchen im Kampf gegen den Kommunismus als Verbündeten ersten Ranges. Die politische Elite und die katholische Kirche wurden durch gemeinsame Interessen eng verbunden. Die wichtigsten von diesen waren das Aufrechterhalten der gesellschaftlichen Ordnung, die Vorbeu-

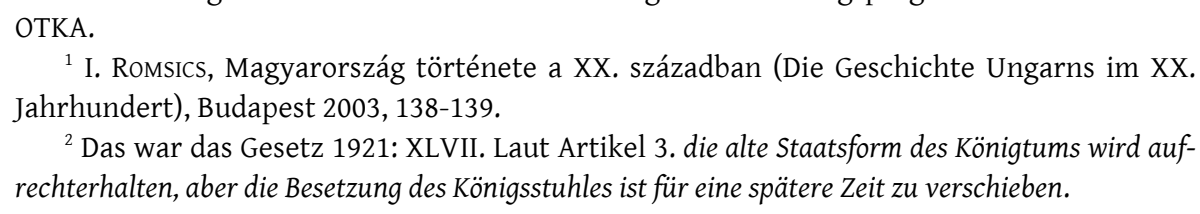

${ }^{1}$ I. Romsics, Magyarország története a XX. században (Die Geschichte Ungarns im XX. Jahrhundert), Budapest 2003, 138-139.

${ }^{2}$ Das war das Gesetz 1921: XLVII. Laut Artikel 3. die alte Staatsform des Königtums wird aufrechterhalten, aber die Besetzung des Königsstuhles ist für eine spätere Zeit zu verschieben.

Der Beitrag ist entstanden mit Unterstützung des Forschungsprogramms NK 83799 von

AHC 46 (2014) 
gung einer eventuellen Machtergreifung der radikalen Linken, und die Revision des Friedensvertrages von Trianon 1920, durch den Ungarn zwei Drittel seines Staatsgebietes verloren hatte. Die führenden Personen der ungarischen Katholiken glaubten daran, dass der wichtigste Grund des Niederganges ihres Vaterland in der religiösen Gleichgültigkeit und der Verbreitung des Materialismus zu finden sei, und sie erwarteten eine gesellschaftliche Erneuerung von den christlichen Werten her. Deshalb trugen sie von Anfang an zu der symbolischen Unterstützung und moralischen Legitimation der Machthaber bei ${ }^{3}$.

\section{Katholizismus und Politik in der Zwischenkriegszeit}

Die Sehnsucht nach territorialer Revision und die Zuneigung zu Großungarn machten sich mit voller Ungezwungenheit in den offiziellen katholischen Ereignissen bemerkbar. Dies veranlasste Nuntius Lorenzo Schioppa, vielleicht unter dem Druck des Publikums, zu einer Geste, die für einen Diplomaten sehr ungewöhnlich war. Als er 1921 in der Stadt Cegléd an einem Festessen teilnahm, hielt eine Rede, in der versicherte, er sei mit der ungarischen Nation völlig eins geworden, und danach, um seine Worte zu demonstrieren, küsste die ungarische Nationalfahne ${ }^{4}$. Ein Jahr später ging er noch weiter. Als er den Katholikentag in Budapest eröffnete, begann seine Rede mit einem Zitat in ungarischer Sprache: Hiszek Magyarország feltámadásában - Ich glaube an der Auferstehung Ungarns ${ }^{5}$. Seine Worte fanden natürlich stürmischen Beifall ${ }^{6}$, weil das Zitat aus dem sogenannten Ungarischen Glaubensbekenntnis stammte, das das populärste Produkt der revisionistischen Propaganda war ${ }^{7}$.

\footnotetext{
${ }^{3}$ G. ADRIÁNYI, Fünfzig Jahre ungarischer Kirchengeschichte 1895-1945, Mainz 1974; N. SPANNENBERGER, Die katholische Kirche in Ungarn 1918-1939. Positionierung im politischen System und "katholische Renaissance", Stuttgart 2006, 39; Cs. FAzEKAS, Collaborating with Horthy. Political Catholicism and Christian Political Organisations in Hungary, 1918-1944, in: M. GeHLER - W. KAISER - H. Wohnout (Hg.), Christian Democracy in 20th century Europe. Wien - Köln - Weimar 2001, 224-249.

${ }^{4}$ Ungarisches Nationalarchiv - Landesarchiv (MNL OL) K 428, Reihe a (Tagesberichte des Ungarischen Telegraphen Korrespondenzbüro) 30. Juni 1921. 8.

${ }^{5}$ Archivio Segreto Vaticano Archivio Nunziatura di Ungheria (ASV ANU) Busta 11. 102104. folio.

${ }^{6}$ Nemzeti Újság. 24. Oktober 1924. 5.

${ }^{7}$ Dieses Gedicht wurde 1920 von einer Lehrerin, Papp-Váry Elemérné Szeréna Sziklay geschrieben, und es wurde auch vertont. Es wurde üblich, dass die Schulkinder die Unterrichtstage mit dem Skandieren des Gedichtes begannen. Der Text der ersten Strophe ist wie folgt: Ich glaube an einen Gott, ich glaube an ein Vaterland / ich glaube an eine ewige göttliche Ge-
} 
Obwohl der Nuntius zunächst behauptete, er wolle keine Politik machen, und er habe das Wort Auferstehung eigentlich nur im Sinn der religiösen Erneuerung benutzt, stiftete seine unbedachte Äußerung ernste diplomatische Verwicklungen. Das rumänische Außenministerium bewertete nämlich seine Rede als einen Beweis für die Parteilichkeit des Heiligen Stuhles zugunsten Ungarns, und erhob deshalb eine förmliche Beschwerde gegen den Nuntius beim Vatikan ${ }^{8}$.

Die Kooperation zwischen dem ungarischen Staat und der katholischen Kirche war aber nicht frei von Spannungen'. Einer der wichtigsten Grundprobleme bedeutete die Frage des Legitimismus. Die Mehrheit der Bischöfe konnte die Entthronung der Habsburger nur mit Mühe akzeptieren. Das ist leicht zu verstehen, denn vor dem ersten Weltkrieg hatte Ungarn einen apostolischen König, nach 1920 aber nur einen Reichsverweser, der zudem noch reformierten Bekenntnisses war ${ }^{10}$. Das wäre früher für das Staatsoberhaupt völlig undenkbar gewesen. Miklós Horthy als Protestant konnte natürlich nicht als Protektor des Katholizismus wirken, wie es die Habsburger vor 1918 taten, und gemäß den staatlichen Gesetzen durfte er auch das oberste Patronatsrecht nicht ausüben ${ }^{11}$. Viele Katholiken konnten Horthy nicht akzeptieren. Bei den Katholikentagen der zwanziger Jahre wurde es zum Beispiel üblich, dass der Sohn des verstorbenen Königs Karl als Otto II., also als legitimer König bejubelt wurde ${ }^{12} .1924$ erhob das Ministerium für Kultus und Bildungswesen beim Fürstprimas János Csernoch Beschwerde, weil die Mehrheit des Klerus an den offiziellen Gottesdiensten anlässlich des Geburtstages des Reichsverwesers nicht teilnahm, und es in den katholischen Schulen an diesen Tag keine Feierlichkeiten gab $^{13}$.

Einige Bischöfe waren überzeugte Royalisten, was sie auch öffentlich zu Erkennen gaben. Der Nuntius informierte zum Beispiel den Heiligen Stuhl

rechtigkeit / ich glaube an die Auferstehung Ungarns. J. VonYó, A Magyar Hiszekegy születése (Die Entstehung des Ungarischen Glaubensbekenntnisses), in: História 1 (2002) 18 -19.

${ }^{8}$ ASV ANU Busta 11. 89. folio. Gasparri an Nuntius Schioppa, 6. Januar 1925; MNL OL K 105. 35. cs. M-2. (Dokumente der Botschaft bei dem Heiligen Stuhl) Außenminister Scitovszky an Botschafter Bornemissza, am. 13. Februar 1925.

${ }^{9}$ Á. v. KLIMó, Impartialität versus Revisionismus? Zum Verhältnis zwischen dem Heiligen Stuhl und Ungarn in der Zwischenkriegszeit, in: J. ZeIDLER (Hg.), Der Heilige Stuhl in den internationalen Beziehungen 1870 - 1939, München 2010 (= Spreti Studien 2), 313.

${ }^{10}$ D. TURBuCz, Horthy Miklós, Budapest 2011, 18.

${ }^{11}$ J. GERGELY, A katolikus egyház története Magyarországon 1919-1945 (Die Geschichte der katholischen Kirche in Ungarn 1919 - 1945), Budapest 1999, 20-25.

${ }^{12}$ Nemzeti Újság. 12. Oktober 1925. 18.

${ }^{13}$ SPANNENBERGER (wie Anm. 3), 50. 
1925 darüber, dass ein Bischof während einer Prozession die Gläubigen mit den folgenden Worten gesegnet hatte: Benedictio Dei Omnipotentis super Regem Nostrum Apostolicum Ottonem ${ }^{14}$. Die Bischofkonferenz war jedoch wesentlich vorsichtiger. Als die legitimistischen Aristokraten 1923 die Kirche darum baten, an den Namenstagen von Königin Zita und Erzherzog Otto, sowie am Todestag von König Karl jährlich einen offiziellen Gottesdienst zu anzuordnen, traf die Bischofskonferenz keine Entscheidung, sondern überließ sie den einzelnen Bischöfen. Sie empfahl nur das Requiem für den verstorbenen König regelmäßig zu feiern, weil man fand, dass dies ohne Befürchtungen stattfinden könnte ${ }^{15}$.

Obwohl Zwei Drittel der Bevölkerung katholisch war, bildeten die Protestanten eine sehr einflussreiche Minderheit, die über signifikante politische und kulturelle Macht verfügte ${ }^{16}$. Die katholische Hierarchie war über diese Situation unzufrieden: der Fürstprimas schlug 1929 der Bischofskonferenz vor, die Kirche solle die Einberufung einer unabhängigen Jury verlangen, die die Verteilung der staatlichen Positionen unter den Konfessionen untersuchen sollte ${ }^{17}$.

Als eine weitere Spannungsquelle kann man das sogenannte Allgemeine Christentum bewerten, das von dem Staat initiiert wurde. Die Regierung wollte nämlich gegenüber der internationalen Desintegration die Einheit des christlichen Ungarns demonstrativ aufweisen. Das Regime erwartete von den Vertretern der verschiedenen Konfessionen, dass sie an den oft veranstalteten staatlichen und militärischen Feierlichkeiten gemeinsam teilnehmen. Dieser Wunsch verursachte gewissenhaften Katholiken ein moralisches Problem, da das Kirchenrecht die Teilnahme an konfessionell

\footnotetext{
${ }^{14}$ K. TóTH, Modernkori katolicizmus vs. neobarokk államegyház. Mi vezetett Cesare Orsenigo nuncius felszólalásához egy magyar püspökkari konferencián? (Moderner Katholizismus vs. neobarockische Staatskirche. Was führte zu der Rede von Nuntius Cesare Orsenigo vor einer ungarischen Bischofskonferenz?), in: T. KLESTENITZ - I. ZOMBORI (Hg.) Litterarum radices amarae, fructus dulces sunt. Tanulmányok Adriányi Gábor 80. születésnapjára (= Studien zum 80. Geburtstag von Gabriel Adriányi), Budapest 2015, 247.

${ }^{15}$ M. BEKE (Hg.), A magyar katolikus püspökkari tanácskozások története és jegyzőkönyvei 1919-1944 között (Die Geschichte und die Protokolle von den Beratungen des ungarischen katholischen Episkopats zwischen 1919 - 1944), München - Budapest 1992, 122.

${ }^{16} \mathrm{~J}$. BRANDT, Konfessionelle und nationale Identität in Ungarn. Die protestantischen Kirchen, in: H. C. MANER - M. Schulze WesSel (Hg.), Religion im Nationalstaat zwischen den Weltkriegen 1918 - 1939, Stuttgart 2002 (= Forschung zur Geschichte und Kultur des östlichen Mitteleuropa 16), 46.

${ }^{17}$ BEKe (wie Anm. 15), 270.
} 
gemischten Veranstaltungen untersagte ${ }^{18}$. Die Lage wurde auch dadurch verschlechtert, dass die Beziehungen zwischen dem Staat und den Kirchen, wie schon auch im Zeitalter des Dualismus, überwiegend durch das Gewohnheitsrecht geregelt wurden, und Ergebnis war ein Konkurrenzkampf unter den Kirchen um die staatliche Unterstützung ${ }^{19}$.

Die Zwischenkriegszeit war außer Zweifel eine Epoche der religiösen Erneuerung in Ungarn, was auch daraus ersichtlich wird, dass damals 15 Diözesansynoden gehalten wurden, während es in den vorherigen fünfzig Jahren dagegen nur 3 gewesen waren ${ }^{20}$. Im Folgenden untersuche ich, wie sich die Beziehungen zwischen dem Staat und der katholischen Kirche in den Quellen der Synoden wiederspiegeln. Die Synoden regelten natürlich das innere Leben der Diözesen, weshalb wir die oben genannten Spannungen vor allem in zwei Bereichen ausmachen können: wie die Synodalgesetzgebung die katholischen Interessen gewährleisten wollte, und wie sie einige symbolische Fragen beurteilte.

\section{Die Frage des Interessenschutzes an den Diözesansynoden}

Die erste Diözesansynode nach dem ersten Weltkrieg wurde 1921 in Vác (Waitzen) gehalten, und sie diente als Muster für die darauffolgenden Synoden ${ }^{21}$. Die hier verabschiedeten Gesetze zeigen, dass die Frage des Interessenschutzes als eine wichtige Aufgabe galt, also das Vertrauen gegenüber dem Staat zweifelsohne nicht bedingungslos war. Laut Diözesangesetz sollten die Kleriker ihren Einfluss im öffentlichen Leben im Interesse ihrer Gläubigen geltend machen, was als kirchliche und patriotische Pflicht beschrieben wurde. Sie sollten die katholische Parteipolitik unterstützen, aber sie sollten zugleich darauf achten, mit dem Volk ihrer Pfarre wegen der Politik nicht in Zwiespalt zu geraten ${ }^{22}$. Diese Verordnung übernahm

\footnotetext{
${ }^{18}$ Kánonjogi Kódex. Kézirat gyanánt (Codex juris canonici. Pro manuscripto) 498.

${ }^{19}$ L. PÉTER, Az állam és az egyház viszonya és a civil társadalom Magyarországon: történeti áttekintés (Die Beziehungen zwischen Staat und Kirche und die Zivilgesellschaft in Ungarn: ein historischer Überblick), Századvég (1997/4), 3-31.

${ }^{20}$ M. GÁRDONYI, Az 1923. évi veszprémi zsinat előkészítő munkálatai (Die Vorbereitungsarbeiten der Synode von Veszprém 1923), in: I. Hermann - B. KarLinszKY - T. L. Varga (Hg.), Corde Aperto. Tanulmányok Kredics László 80. születésnapjára, Veszprém 2012, 50.

${ }^{21}$ A. F. LENAR, A váci egyházmegye Hanauer Árpád István püspöksége (1919-1942) alatt (Die Diözese Vác unter dem Episkopat von Bischof Árpád István Hanauer), Budapest 2014 (= Diss. phil. Eötvös Loránd Universität), 29-30.

${ }^{22}$ Decreta Synodalia. Az 1921. évben tartott váczi egyházmegyei zsinaton hozott egyházmegyei törvények (= Diözesangesetze der Diözesansynode von Vác, gehalten in 1921), Budapest 1921, 14-15.
} 
auch die Synode von Veszpém 1923. Sie wurde dort damit begründet, es sei antisozial und daher zu verurteilen, dass die Kleriker am Leben ihrer Gemeinde nicht teilnehmen wollten. Die Geistlichen sollten die Laienmitglieder der Gemeindeverwaltungen im Interesse der katholischen Gemeinschaft orientieren ${ }^{23}$.

Der Synode von Vác ist auch interessant, weil sie beim Innenminister einen Antrag einreichte, in dem sie den Einfluss der Kirche in den Gemeindeverwaltungen sichern wollte, und sie schlug vor, die Pfarrer seien von Amts wegen Mitglieder der Verwaltungen. In der Begründung verurteilte die Synode, dass das Gesetz, das den Verwaltungsdienst der Hauptstadt neu organisierte, keinen Platz für die Pfarrer in der Stadtverwaltung vorsah. Sie argumentierte mit der konservativen Macht der Religion, die Quelle der selbstlosen Vaterlandsliebe sei. Der Antrag erreichte aber keinen Erfolg ${ }^{24}$.

Die Kirche sollte also bei entsprechender Gelegenheit ihre Interessen unmittelbar im öffentlichen Leben vertreten können. Diese Strategie lebt während der ganzen Horthy-Ära weiter: die Beschlüsse der Synode von Pannonhalma im Jahre 1940 schrieben zum Beispiel vor, der Kleriker solle seinen Einfluss im Leben seiner Gemeinde zur Geltung bringen und die weltlichen Behörden dazu bewegen, an der Förderung des religiösen Lebens Anteil zu nehmen. Er solle also mit den führenden Kreisen der Gesellschaft Kontakte halten, aber er dürfe inzwischen seine Aufgaben als Geistlicher nicht vernachlässigen ${ }^{25}$.

Die Weltwirtschaftskrise beeinflusste von 1929 an auch die Politik in Ungarn. Die Verschlechterung der wirtschaftlichen Bedingungen führte zur Verstärkung des Rechtsradikalismus (und am Anfang der 1930er Jahre gewannen auch die Sozialdemokraten an Einfluss, doch blieb dies eine vorübergehende Erscheinung) ${ }^{26}$. Die Synode der Erzdiözese Eger (Erlau) stellte 1931 fest: jetzt gibt es gegen die Kirche und ihre Dogmen, gegen das Vaterland und

${ }^{23}$ Egyházmegyei határozatok és törvények. Decreta almae dioecesis Wespremiensis anno 1923. diebus 19-21. Junii in synodo dioecesana publicata et approbata (Diözesanbeschlüsse und Gesetze), Veszprém 1923, 10-12.

${ }^{24}$ A. LÉNÁR, Váci egyházmegyei zsinatok Hanauer Árpád István püspöksége alatt (19191942) (Diözesansynoden in Vác unter dem Episkopat von Bischof Árpád István Hanauer), in: M. BALOGH - Sz. VARGA - L. VÉRTESI (Hg.), Katolikus zsinatok és nagygyűlések Magyarországon a 16-20. században, Pécs - Budapest 2014 (= Seria Historiae Dioecesis Quinqueecclesiensis $10)$.

${ }^{25}$ Decreta Synodalia. Az 1940-ben tartott Pannonhalmi Egyházmegyei zsinaton hozott Egyházmegyei Törvények (Die auf der Diözesansynode von Pannonhalma 1940 verabschiedeten Diözesangesetze), Győr 1940, 16.

${ }^{26}$ TURBUCz (wie Anm. 10), 127-128. 
seine Gesetze seitens Personen und ganzer Institutionen planmäßige und ständige Agitation, deshalb sollen sich die Leiter und Hirten des Volkes an die Höhe ihrer Berufung erheben ${ }^{27}$. Den Beschlüsse gemäß sollten sich die Kleriker wohl nicht direkt in die Politik einmischen, denn sie könnten auf diese Weise ihre Gläubige, die andere Ideen haben, von sich entfremden. Sie bekamen aber die Aufgabe: Die feindseligen Bewegungen beachten, und nach der Bewahrung des Glaubens und der bürgerlichen Ordnung zu streben ${ }^{28}$.

Sie sollten ferner die Arbeit der verschiedenen gesellschaftlichen Vereine aufmerksam verfolgen, und nicht mit geistlicher Lehre, sondern eher mit dem treues Interesse zeigenden Umgang und mit unterhaltsamen Vorlesungen die Samen des Evangeliums verbreiten. Sie sollten die katholischen Vereine und christlich-sozialen Gewerkschaften steuern, und sie als ein Mittel des Patriotismus und der Anhänglichkeit gegenüber der Kirche einsetzen ${ }^{29}$.

Die Synode von Győr stellte 1935 fest, dass die Teilnahme an der Politik ein Recht der Kleriker sei, und sie schrieb vor, dass sie zu den weltlichen Behörden gute Beziehungen pflegen sollen. Es sei ferner wünschenswert, an der Arbeit der Gemeinde- und Stadtverwaltungen teilzunehmen. In diesem Fall sind aber die Mahnungen interessanter als die Erlaubnisse. Die Synode untersagte nämlich den Klerikern, als Redner oder Werbepersonen irgendeiner Partei eine Rolle einzunehmen ${ }^{30}$. Da in diesem Jahr einerseits die Umorganisierung der Regierungspartei zu einer modernen Massenpartei (Partei der Nationalen Einheit) unter der Leitung des Ministerpräsidenten Gyula Gömbös begann, wobei die Regierung auch die Mitarbeit des Klerus in Anspruch nehmen wollte, und andererseits die Oppositionsparteien nach ihrer großen Niederlage an den Parlamentswahlen in Passivität verfielen $^{31}$, können wir dieses Gesetz als einen Beweis dafür ansehen, dass die Synode damit vor allem die Regierungspartei bändigen wollte.

Die Synode untersagte dabei strengstens die Erörterung von politischen Fragen auf den Kanzeln, mit der Ausnahme von Fragen, die den Glauben und die Sitten des Volkes betreffen, zum Beispiel im Fall der Schulgesetze und des Familienrechtes. Die Pfarrer sollten über Vaterlandsliebe als ka-

\footnotetext{
${ }^{27}$ Az 1931. évi egri egyházmegyei zsinat határozatai és törvényei (Die Beschlüsse und Gesetze der Diözesansynode von Eger, gehalten im Jahre 1931), Eger 1931, 1.

${ }^{28}$ DS Eger 1931, 6.

${ }^{29}$ DS Eger 1931, 53.

${ }^{30}$ Az 1935. évi győri egyházmegyei zsinat határozatai (Die Beschlüsse der Diözesansynode von Győr, gehalten 1935), Győr 1935, 15.

${ }^{31}$ J. GERGELY, A keresztényszocializmus Magyarországon (1924 - 1944) [Der Christliche Sozialismus in Ungarn (1924 - 1944)], Gödöllo” 1993, 105.
} 
tholische Pflicht sprechen, aber sie sollten gegenüber dem aufkommenden, das Heidentum als Vorbild nutzenden, übertriebenen Nationalismus die katholische Lehre energisch vertreten ${ }^{32}$.

Dieser Aufruf war zweifelsohne äußerst zeitgemäß, denn einige verdächtige religiöse Ansichten wurden damals bei den politischen Rechtsradikalen immer populärer, Schamanen und Magier versuchten die ehemalige ungarische Urreligion auferstehen lassen ${ }^{33}$. Ihren Einfluss zeigt auch ein Beschluss der Synode von Esztergom (Gran) 1941, der vorschrieb, der Pfarrer dürfe bei der Taufe nicht akzeptieren, wenn die Eltern ihrem Kind einen solchen Namen geben wollen, der mit der christlichen Religion im Widerspruch steht $t^{34}$. Dies war strikter als die Vorschrift des allgemeinen Kirchenrechtes, die in diesem Fall von dem Pfarrer erwartete, dass er dem Kind einen zweiten Namen nach einem Heiligen geben sollte ${ }^{35}$.

Die Synode von Győr im Jahre 1935 schrieb auch vor - im scharfen Kontrast zu der chauvinistischen, irredentistischen Stimmung des Zeitalters, aber mit einer Vorahnung des kommenden Weltenbrandes -, dass im Fall eines Krieges die Pfarrer auf den Kanzeln den Glauben des Volkes an das Erbarmen Gottes anregen sollten, doch sie dürfen nichts sagen, was Hass gegen den Feind entfachen könnte ${ }^{36}$.

Nachdem der Weltkrieg tatsächlich ausgebrochen war (der Krieg begann für Ungarn 1941 mit der Aggression gegen Jugoslawien ${ }^{37}$ ), formulierten die gesetzgebenden Versammlungen der Kirche ihre Verordnungen nicht immer so eindeutig. 1941 forderte die Synode von Esztergom die Geistlichen noch ausdrücklich auf, die Anforderungen von Behörden, die mit den göttlichen oder kirchlichen Gesetzen im Widerspruch stehen, entschlossen abzulehnen ${ }^{38} .1942$ aber formulierte die Synode von Eger ihre Erwartungen in recht unbestimmter Weise: Der Kleriker soll im Schutze der ge-

\footnotetext{
${ }^{32}$ DS Győr, 34.

${ }^{33}$ Diese Bewegung bekam die Inspiration vor allem von den Ideen des Turanismus, und wurde von dem Journalisten Béla Balázs Szépvizi (1871-1934) geführt. Er wollte seine Ansichten mit seiner Monatsschrift (Napsugár. Monatschrift für AltungarischeVolkskunde) seit 1925 popularisieren, und in der Stadt Gödöllö eine selbstständige Kirche organisieren. G. M. MERVA, Írók és múzsák Gödöllőn (Schriftsteller und Musen in Gödöllő), Gödöllő 2013, 201.

${ }^{34}$ Az esztergomi föegyházmegyei zsinat (1941. nov. 11-12.) határozatai (Die Beschlüsse der Synode von der Erzdiözese Esztergom), Budapest 1942, 48.

${ }^{35}$ Kánonjogi Kódex (wie Anm. 18), 351.

${ }^{36}$ DS Győr, 34.

${ }^{37}$ TURBucz (wie Anm. 10), 169-173.

${ }^{38}$ DS Esztergom, 12.
} 
rechten Angelegenheiten ernsthaft und auf edle Weise handeln, aber die Liebe zur Wahrheit darf niemanden zu solchen Taten oder Behauptungen anregen, die die Wahren mit Missfallen empfangen würden. Die weise Mäßigung ist der untrennbare Begleiter der Tugend ${ }^{39}$.

Die Synodalbeschlüsse zeigen, dass die Katholiken dem staatlichen Schulsystem auch nicht trauten, obwohl die Gesetze des Horthy-Regimes ausdrücklich deklariert hatten, das Bildungswesen stehe vollständig auf christlichen Grundlagen ${ }^{40}$, und der Kultusminister betonte sogar, die ungarische nationalistische Kulturpolitik kann auf die Mitwirkung unserer historischen Kirchen nicht verzichten ${ }^{41}$. Beide Seiten hatten die Absicht, die Ungarn zur kulturell überlegensten Nation des Donaubeckens zu machen ${ }^{42}$.

Der Klerus war jedoch oft misstrauisch. In Vác schrieb zum Beispiel die Synode vor, die katholischen Schulen sollen gegenüber den staatlichen immer wettbewerbsfähig sein, nicht nur auf dem Gebiet des religiösen Unterrichts, sondern auch hinsichtlich der Lehrkräfte, der Infrastruktur und der Ausstattung. Die Pfarrer sollten danach streben, dass die katholischen Kinder nur katholische Schulen besuchen. An den Orten, wo es nur staatliche Schulen gebe, sollten die Kleriker zu verhindern suchen, dass die Schule im Gegensatz zu den christlichen Prinzipien gerät ${ }^{43}$.

Die Synode von Székesfehérvár (Stuhlweißenburg) erwartete von den Religionslehrern die Teilnahme an den Lehrerkonferenzen in den staatlichen Schulen, um ihre Kollegen in die gute Richtung leiten zu können ${ }^{44}$. Die Synode von Pécs (Fünfkirchen) regte die Religionslehrer an, in den staatlichen Schulen besonders eifrig zu arbeiten, um die an den anderen Unterrichtsstunden manifestierte religiöse Gleichgültigkeit oder Antiklerikalis-

\footnotetext{
${ }^{39}$ Az 1942. évi egri egyházmegyei zsinat határozatai és törvényei (Die Beschlüsse und Gesetze der Diözesansynode von Eger, gehalten 1942), Eger 1942, 10.

${ }^{40} \mathrm{P}$. T. NAGY, Járszalag és aréna. Egyház és állam az oktatáspolitika erőterében a 19. és 20. századi Magyarországon (Leine und Arena. Staat und Kirche im Spannungsfeld der Bildungspolitik in Ungarn des 19. und 20. Jahrhunderts), Budapest 2000, 115 - 116.

${ }_{41}$ Á. v. KLImó, Trianon und der Diskurs über nationale Identität in "Rumpf-Ungarn" (1918-1938) in: A. HILGER - O. VROCHEM (Hg.), Die geteilte Nation: Nationale Verluste und Identitäten im 20. Jahrhundert, München 2013. 25.

${ }^{42}$ KLImó, Inpartialität versus Revisionismus? (wie Anm. 9), 316.

${ }^{43}$ DS Vác 1921, 63; Decreta Synodalia. Az 1930. évben tartott II. váciegyházmegyei zsinaton hozott egyházmegyei törvények (Die auf der im Jahre 1930 gehaltenen II. Diözesansynode von Vác verabschiedeten Diözesangesetze), Rákospalota 1931, 118.

${ }^{44}$ Decreta Synodalia. Az 1934. évi június 20-tól 22-ig Székesfehérvárott tartott székesfehérváregyházmegyei zsinaton hozott egyházmegyei törvények (Die Diözesangesetze der vom 20. - 22. Juni in Székesfehérvár gehaltenen Diözesansynode), Székesfehérvár 1935, 56.
} 
mus zu kompensieren. Die Pfarrer sollten ferner erreichen, dass die Katholiken ihrem Bevölkerungsanteil angemessen in den Lehrerschaften und in den Schulverwaltungen der staatlichen Schulen vertreten werden ${ }^{45}$.

Die Synode von Eger bestätigte, es sei Aufgabe des Pfarrers, das Interesse der Gläubigen für die katholische Schule aufrechtzuerhalten. Deshalb sollte er einmal pro Jahr über die katholische Schule und über ihre Bedeutung für das Individuum, die Kirche und das Vaterland eine Predigt halten. Der Pfarrer sollte ferner auch in der Verwaltung der staatlichen Schulen die Interessen der Kirche wahrnehmen. Wenn zum Beispiel die Wahl eines Schullehrers für die Kirche nachteilig erschien, sollte er beim Kultusministerium einen Einspruch erheben, mit der Begründung, dass man bei Ernennung von Lehrern auch auf den konfessionellen Anteil der Schüler Rücksicht nehmen müsse. Der Pfarrer sollte sodann eine Kopie des Einspruches unverzüglich an die Diözesanleitung schicken ${ }^{46}$.

In der Frage der Kirchensteuer gab es Problemfälle, da die Mitglieder der Kirche in einigen Fällen, wenn die Summe der Steuer in Frage gestellt wurde, die Hilfe des Staates für sich beanspruchen wollten. Das zeigt der Beschluss der Synode von Szombathely (Steinamanger), die feststellte, die Kirchengemeinde dürfe eine Kirchensteuer nach der Genehmigung der Diözesanbehörden ohne weiteres auferlegen. Die Laienverwaltung habe kein Recht, sie zu verändern, sie dürfe allenfalls Einspruch beim Kultusministerium erheben, falls sie den Steuersatz zu hoch finden sollte ${ }^{47}$.

Die Frage Gebrauches der jeweiligen Sprache bei kirchlichen Zeremonien führte nicht selten zu Konflikten, da der Staat die Sprache der Predigt und der Gesänge als eine Mittel der Magyarisierung der nationalen Minderheiten betrachteten, während die Minderheiten ihrerseits ihre Rechte unbedingt wahren wollten. Jakob Bleyer, Wortführer der Ungarndeutschen, schrieb zum Beispiel 1930 an den Ministerpräsidenten einen Brief, in dem er dagegen protestierte, dass in zahlreichen Dörfern und Städten die deutschen Schulkinder obligatorisch verpflichtet waren, an Messen mit ungarischer Predigt teilzunehmen, obwohl es auch Messen mit Gebrauch deutscher Sprache gab. Die Regierung und auch die Minderheiten wollten die Hierarchie jeweils auf ihre Seiten ziehen, aber die Bischöfe waren auf

\footnotetext{
${ }^{45}$ Statuta Synodalia. Pécsegyházmegyei zsinati határozatok. Megállapította az 1936. évi egyházmegyei zsinat (Beschlüsse der Synode von Pécs, verabschiedet durch die Diözesansynode 1936), Pécs 1936, 40.

${ }^{46}$ DS Eger 1931, 95-96.

${ }^{47}$ A szombathelyi egyházmegye zsinati határozatai (Die Synodalbeschlüsse der Diözese Szombathely), Szombathely 1927, 145.
} 
der Grundlage des Kirchenrechts der Meinung, diese Frage sei ausschließlich eine Angelegenheit der Kirche, und allein der Episkopat hätte das Recht, eine diesbezügliche Entscheidung zu treffen ${ }^{48}$. Die Synode der Erzdiözese Esztergom 1941 formuliert klar und deutlich: der öffentliche Gottesdienst wird von der Kirche geleitet, vor allem durch die S. Congr. Rituum. Ihre Entscheidung muss man deshalb mit Respekt annehmen. In Angelegenheiten der Fragen der Zeremonien der Kirche hat die weltliche Macht keine Kompetenz, nicht einmal in Fragen der Sprache $e^{49}$.

Am Ende der Periode warf auch die Taufe Probleme auf. Das Parlament von Ungarn schuf nämlich nach 1938, teils als Folge der Radikalisierung der Massenstimmung eine Reihe von diskriminierenden Judengesetzen, welche die Anzahl der Juden in freien Berufen, in der Verwaltung sowie in Handel und Industrie zunächst auf 20 Prozent, später bis auf 6 Prozent reduzierten. Dabei wurden ihre politischen Rechte eingeschränkt. Das dritte der antisemitischen Gesetze (1941) verbot die Eheschließung (und sogar den Geschlechtsverkehr) zwischen Juden und Christen ${ }^{50}$. Dieses Gesetz definierte solche Personen als Juden, bei denen mindestens zwei Großeltern als Mitglieder der israelitischen Konfession geboren wurden. Trotz der Tatsache, dass es damals schon keine juristische Relevanz mehr hatte, gab es aber auch solche Personen, die in der Bekehrung zum Christentum einen Ausweg sahen. Die Synode von Esztergom schrieb den Klerikern vor, bei Religionswechsel zugunsten des katholischen Glaubens den Konvertiten jede mögliche Hilfe zu geben. Sie sollten dabei die offiziellen Formen einhalten, was den Prozess ein bisschen verlängerte. Die Pfarrer sollten dann darauf achten, dass die Tatsache der Konversion auch in den staatlichen Matrikeln eingeschrieben wird. Die Kleriker sollten die Taufbewerber mit christlicher Nächstenliebe empfangen, sie in ihrer Absicht bestärken, und ihnen den nötigen Unterricht erteilen. Die Pfarrer sollten ferner über alle Personen, die um die Taufe ersuchen, eine Meldung an die Kirchenleitung senden und danach deren Instruktionen gewissenhaft folgen ${ }^{51}$.

\footnotetext{
${ }^{48}$ A. GRósz, A templomi német nyelvhasználat ügye a két világháború közötti Magyarországon (Die Frage des kirchlichen deutschen Sprachgebrauches im Ungarn der Zwischenkriegszeit), in: Litterarum radices amarae, fructus dulces sunt (wie Anm. 14), 257.

${ }^{49}$ DS Esztergom, 91.

${ }^{50}$ Romsics (wie Anm. 1), 258-259.

${ }^{51}$ DS Esztergom, 4-5.
} 
Symbolische Konflikte um die konfessionelle Frage

Da viele Katholiken den Eindruck hatten, der Protestantismus habe den Staat für sich vereinnahmt, stellten sich ab der zweiten Hälfte der 1920er Jahre immer heftigere katholisch-protestantische Kontroversen. Der Präsident des Katholikentages behauptete 1926 in seiner Eröffnungsrede, dass die Katholiken ihre Interessen nicht ihrer Bevölkerungszahl angemessen durchsetzen könnten, und verlangte deshalb eine gerechte Berücksichtigung für seine Glaubensgemeinschaft. Daneben sorgte auch das Bestreben des Heiligen Stuhls für Spannungen, die gemischten konfessionellen Feierlichkeiten zu beseitigen.

Die Protestanten waren schon am Anfang der 1920er Jahre mit der Haltung der katholischen Kirche unzufrieden, weshalb der Wohlstandsminister, der katholische Geistliche József Vass, 1922 vor der Sitzung der Nationalversammlung die Haltung seiner Kirche verteidigte. Er meinte, man kann nationale und völkische Einheit wollen, aber eine religiöse Einheit sei nicht zu schaffen. Er schlug vor, dass die Kirchengemeinschaften an solchen Feierlichkeiten, die die Geschlossenheit der Nation zum Ausdruck bringen, in der Zukunft ihre Feierlichkeiten parallel in ihren Gotteshäusern halten sollen, und danach die Bürger zusammenkommen und eine gemeinsame, weltliche Feier halten ${ }^{52}$. Dies nahm auch der ungarische Episkopat mit großer Sympathie auf, und die Bischofskonferenz veranlasste im Oktober 1924 eine Verordnung in dieser Frage im Sinne des Vorschlages von Vass ${ }^{53}$.

Auch Kardinalstaatssekretär Pietro Gasparri fand die Idee annehmbar, und er forderte den Nuntius auf, die Regierung um eine schriftliche Garantie zu bitten. Schioppa wurde diesbezüglich mehrfach bei Minister Vass vorstellig, doch konnte er für Heiligen Stuhl keine Garantie erhalten. Der neue Nuntius, Cesare Orsenigo bekam 1925 von Gasparri die Instruktion, den ungarischen Episkopat zu ermahnen, sich an das Kirchenrecht zu halten. Er nutzte den Katholikentag dazu aus, wo er eine informelle Ansprache an die Bischöfe richtete. Sie machten aber ihn darauf aufmerksam, ihre Lage sei kompliziert, wenn sie - vor allem auf dem Lande - gewisse gesellschaftliche und Höflichkeitserwartungen erfüllen sollen, wo die protestantischen Pastoren sie regelmäßig aufsuchen ${ }^{54}$.

\footnotetext{
${ }^{52}$ Tóтн (wie Anm. 14).

${ }^{53}$ BEKE (wie Anm. 15), 144.

${ }^{54}$ Tótн (wie Anm. 14).
} 
Die Intervention des Nuntius blieb also erfolgslos, weshalb er zu einem ungewohnten Mittel griff, indem er den versammelten Episkopat persönlich aufsuchte. Im März 1926 bat Nuntius Cesare Orsenigo im Auftrag von Staatssekretär Gasparri die Bischofkonferenz darum, mit der Tradition zu brechen, auch Pastoren und Gläubige von anderen Konfessionen zu den an Nationalfeiertagen gehaltenen Messfeiern einzuladen, da dies zu religiösem Indifferentismus führen könnte ${ }^{55}$.

Obwohl der Episkopat diese Befürchtungen für nicht begründet hielt, veröffentlichten drei Bischöfe Rundbriefe, in denen sie die Regeln verschärften $^{56}$. Im September 1926 löste die Tatsache einen Skandal aus, dass der Pfarrer der St. Stephan Basilika in Budapest sich weigerte, die Fahne eines christlich-sozialen Verbandes zu segnen, die vorher auch von einem reformierten und einem evangelischen Pastor gesegnet worden war. Dieser Gebrauch hieß damals Wandersegen ${ }^{57}$.

Diese Ereignisse hatten ernste Konsequenzen: Der österreichische Botschafter in Budapest meinte zum Beispiel, dass sie einen bedeutenden Konflikt unter den Konfessionen mit sich brächten ${ }^{58}$. Die Protestanten beurteilten die Ereignisse als Beweis für die staatskirchlichen Neigungen der Katholiken und als Anfang eines Kulturkampfes ${ }^{59}$. Auch der reformierte Ministerpräsident István Bethlen brachte seine Besorgnis zum Ausdruck ${ }^{60}$.

Die Spannungen verstärkten sich noch weiter, wozu es auch beitrug, dass Fürstprimas János Csernoch, der gegenüber dem Staat stets kompromissbereit handelte, im Jahre 1927 starb $^{61}$. Für seinen Nachfolger, Jusztinián Serédi hatte das Kirchenrecht oberste Priorität ${ }^{62}$, und so verbot er mit größerer Strenge die politische Aktivität der Geistlichen ${ }^{63}$. Auch die Synoden dieser Periode zeigen den neuen Trend.

Die nächste Synode wurde 1927 in Szombathely abgehalten. Es fällt auf, dass sie in den Synodalbeschlüssen ein selbstständiges Kapitel einfügte, die die Fragen des Verhaltens gegenüber Gläubigen von anderen Konfessionen

${ }^{55} \mathrm{Ebd}$.

${ }^{56}$ MNL OL K 105. 35. cs. M-5. Chiffriertes Telegramm aus Budapest 5. November 1926.

${ }^{57}$ MNL OL K 15. 35. cs. M-5. László Ravasz reformierter und Sándor Raffay evangelischer Superintendent an Ministerpräsidenten Bethlen, 25. Oktober 1926.

${ }^{58}$ SPANNENBERGER (wie Anm. 3), 75.

${ }^{59}$ Az Est. 8. Oktober 1926.. 1-2.; Pesti Hírlap. 8. Oktober 1926. 6.

${ }^{60}$ Nemzeti Újság. 19. Oktober 1926. 1.

${ }^{61}$ A. Lepold, Csernoch János, Bécs 1963, 74.

${ }^{62}$ B. CsíkY, Serédi Jusztinián hercegprímási tevékenysége (Die Tätigkeit von Jusztinián Serédi als Fürstprimas), Budapest 2010 (= Diss. phil. Eötvös Loránd Universität).

${ }^{63}$ KLImó, Impartialität versus Revisionismus? (wie Anm. 9), 319. 
regelte. Die Katholiken mit Liebe und Wohlwollen ihren Mitmenschen begegnen, lehrte die Synode, aber sie sollten vorsichtig sein und Vorsorge treffen, dass ihr eigener Glaube und die Intensität ihres religiösen Lebens nicht nachließen. Im Einklang mit dem Codex Juris Canonici ${ }^{64}$ wurde verboten, an nicht katholischen religiösen Veranstaltungen teilzunehmen, und die Gläubigen durften sich nicht einmal die Übertragungen von protestantischen Gottesdiensten im Radio anhören. Die Priester durften natürlich keine gemeinsamen Gottesdienste und Feierlichkeiten veranstalten ${ }^{65}$.

Die Synode von Székesfehérvár verbot, anlässlich der Nationalfeiertage an demselben Ort zusammen oder nacheinander katholische und protestantische Gottesdienste zu abzuhalten. Sie verbot auch die erwähnten sogenannten Wandersegen. Die Synode schlug vor, jede Konfession solle in ihrer eigenen Kirche Gottesdienste halten, und die Gläubigen können danach an der weltlichen Feierlichkeit gemeinsam teilnehmen ${ }^{66}$, womit sie den Vorschlag von Minister József Vass in die Tat umsetzen wollte. Die Synode von Győr 1935 schrieb vor, Fahnen und Zeichen von Vereinen dürften nur dann gesegnet werden, wenn der Verein aus kirchlicher Sicht einwandfrei sei ${ }^{67}$. Die Synode von Esztergom war noch rigoroser, indem sie anordnete, dass ausschließlich Fahnen von katholischen Vereinen gesegnet werden dürften ${ }^{68}$. Sie ermahnte ferner die Pfarrer, keine liturgischen Gewänder zu tragen, wenn sie an weltlichen Feierlichkeiten teilnehmen ${ }^{69}$.

Die zweite Synode der Erzdiözese Eger 1942 führte sogar aus, ein Kleriker begehe einen ernstes Vergehen, wenn er für den konfessionellen Frieden die katholische Glaubenslehre aufopfere, oder mit seinem Verhalten den religiösen Indifferentismus fördere. Es wurde kategorisch untersagt, an Empfängen von Vertretern der protestantischen Glaubensgemeinschaften teilzunehmen oder die im Besitz der katholischen Kirche stehenden Gebäude anderen Konfessionen überlassen ${ }^{70}$. Das alles kann man mit den Verhältnissen des zweiten Weltkrieges erklären, wo die staatlichen Behörden zum Schutze der gesellschaftlichen Kohäsion den konfessionellen Frieden unbedingt sicherstellen wollten.

\footnotetext{
${ }^{64}$ Kánonjogi Kódex (wie Anm. 18), 498.

${ }^{65}$ DS Szombathely, 135.

${ }^{66}$ DS Székesfehérvár, 120-121.

${ }^{67}$ DS Győr, 161.

${ }^{68}$ DS Esztergom, 77.

${ }^{69}$ DS Esztergom, 92.

${ }^{70}$ DS Eger, 1942. 11.
} 
Als Beispiel für die Schärfe der symbolischen Konflikte mag dienen, wie in vielen Fällen auch darüber diskutiert wurde, ob man während einer heiligen Messe die Nationalhymne singen dürfe oder nicht. Den Text der Hymne hatte nämlich der reformierte Dichter Ferenc Kölcsey verfasst, und ein Vers, Denn dies Volk hat schon gebüßt für Vergangenes und Kommendes, war für einige Kleriker aus theologischer Sicht problematisch. Es kam vor, dass die Gläubigen am Ende der Messe die Hymne zu singen begannen, worauf der Pfarrer sich in die Sakristei zurückzog. Dies fanden viele Gläubige anstößig, und in einem solchen Fall wurde auch József (Pehm) Mindszenty, der spätere Fürstprimas (1945-1974) kritisiert, der damals Stadtpfarrer von Zalaegerszeg war. Am 15. März 1934, dem Gedenktag der Revolution von 1848 (gegen die Habsburger) verursachte er einen Skandal, weil er das Gotteshaus verließ, während die Gläubigen die Hymne sangen. Der Redakteur der Lokalzeitung äußerte seine Verwunderung darüber, dass Mindszenty im Gegensatz zu dem Fall des Nationalfeiertags an den Namenstagen von Otto von Habsburg immer feierliche Messen zelebrierte ${ }^{71}$.

Die Synode von Györ schrieb deshalb vor, wenn die Gemeinde in der Kirche die Nationalhymne singen möchte, dann sei dieser Wunsch zu erfüllen, und der Pfarrer sollte das am Altar abwarten ${ }^{72}$. Die Synode von Pécs war strenger und erlaubte das Singen der Hymne nur anlässlich der Nationalfeiertage. Das hatte sicherlich auch historische Gründe, da in der Diözese schon am Anfang des 20. Jahrhunderts über diese Frage viel diskutiert worden war $^{73}$. Ferner verbot sie kategorisch in den Gotteshäusern den irredentistischen Marsch, das Ungarische Glaubensbekenntnis, zu singen ${ }^{74}$.

Als Zusammenfassung können wir feststellen, dass Spuren der Konflikte zwischen Kirche und Staat in den Diözesangesetzen deutlich auszumachen sind. Sie waren zwar Verbündete, aber die allgemeine Vermutung katholischerseits, der Staat diene vor allem dem Protestantismus, führte zu beträchtlichen Spannungen. Die Synoden unterstützten die Wahrung der Interessen der katholischen Seite, und grenzten im Bereich der symbolischen Politik die Kirche von den übertriebenen Erwartungen der Regierung und der nationalistischen politischen Kräfte $a b$. Der eigentliche

\footnotetext{
${ }^{71}$ Dieser Artikel führte zu einem Presseprozess zwischen Mindszenty und dem Redakteur. Historisches Archiv der Staatssicherheitsdienste 3.1.9. V - 700/40. 70. folio.

${ }^{72}$ DS Győr, 76.

${ }^{73}$ Z. KovÁcs, Hetyey Sámuel pécsi püspök (1897-1903) (Sámuel Hetyey, Bischof von Pécs), in: T. FEDELES - Z. KOVÁcs - J. SÜMEGI (Hg.), Egyházi arcképek a pécsi egyházmegyéből, Pécs 2009, 145-151.

${ }^{74}$ DS Pécs, 65.
} 
Grund des Konflikts war, dass das Horthy-Regime auf eine Eliminierung der konfessionellen Unterschiede bedacht war. Demgegenüber wollte die katholische Kirche die Identität ihrer Gläubigen stärken und möglichst auch die Übertreibungen des Irredentismus bändigen. 